Int. J. Dev. Biol. 56: 127-133

doi: $10.1387 / \mathrm{ijdb} .113432 \mathrm{mi}$

\title{
Stem cell protection mechanisms in planarians: the role of some heat shock genes
}

\author{
MARIA-EMILIA ISOLANI, MARIA CONTE\#, PAOLO DERI and RENATA BATISTONI* \\ Department of Biology, University of Pisa, Pisa, Italy
}

\begin{abstract}
Planarians contain a large population of stem cells, named neoblasts, and use these for continuous turnover of all cell types. In addition, thanks to the amazing flexibility of these cells, planarians respond well to the effects of stressful situations, for example activating regeneration after trauma. How neoblasts respond to stress and support continuous proliferation, maintaining long-term stability, is still an open question. Heat shock proteins (HSPs) are a complex protein family with key roles in maintaining protein homeostasis, as well as in apoptosis and growthrelated processes. We recently characterized some planarian homologs of $h s p$ genes that are highly expressed in mammalian stem cells, and observed that some of them are critical for neoblast survival/maintenance. The results of these studies support the notion that some HSPs play crucial roles in the modulation of pathways regulating stem cell activity, regeneration and tissue repair. In this review we compare the evidence available for planarian $h s p$ genes and focus on questions emerging from these results.
\end{abstract}

KEY WORDS: planaria, stem cell, heat shock gene, gene expression, RNAi

\section{Introduction}

Planarians have emerged as a valuable model system in regeneration and stem cell research because of their remarkable ability to regenerate complete worms from small body fragments (Gentile et al., 2011). In these organisms regeneration dynamics and tissue homeostasis rely on the availability of a population of adult stem cells, named neoblasts. Neoblasts have the potential to self-renew and to give rise to all cell types of the body, providing us with a unique system to study the complex relationships between the mechanisms that regulate the maintenance of homeostasis and the reactivation of developmental programs during regeneration. Regeneration is a common phenomenon in planarians. After an injury, the initial step of regeneration is the wound healing, necessary to prevent disruption of body fluid balance, and to reduce the invasion of pathogens. Then neoblasts proliferate at the injury site to form the blastema, which is an accumulation of cells showing an undifferentiated morphology. Blastemal cells will eventually differentiate and regenerate the missing parts (Handberg-Thorsager et al., 2008). In addition to the impressive regenerative power, planarians are always in the process of remaking their body through continuous cell turnover, growing and shrinking in volume and length depending on food availability. Unlike most other animals, the body patterning mechanisms are always active in planarians and this raises the question of how their stem cells can support continuous proliferative activity maintaining long-term stability. The impact of time and age on adult stem cells has recently been studied in mammals and the concept of a generalized decline in tissue regenerative responses, associated with depletion and/or a loss of function of adult stem cells, is beginning to emerge (Rando, 2006; Sahin and Depinho, 2010). The stem cell strategies in coping to exposure to injury or other critical stress conditions remains to be defined in planarians.

The cellular stress response represents the main mechanism by which the organisms adapt and survive to the effects of environmental and physiological stressors during their lifetime. Central to this mechanism is the function of a conserved group of stress-related proteins, including the heat shock proteins (HSP) (Lindquist and Craig, 1988). HSPs are a set of evolutionarily ancient and conserved molecular chaperones with a relevant role in

Abbreviations used in this paper: ES, embyonic stem; hsp, heat shock protein.

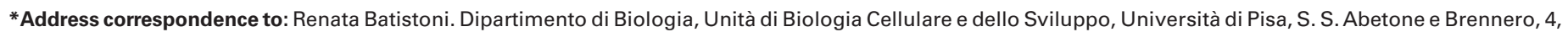
56127 Pisa, Italy. Tel: +39-050-221-1492. Fax: +39-050-221-1495. E-mail: rbatistoni@biologia.unipi.it

\#Present Address: CIG Centro Interdipartimentale “Galvani", Dip. Patologia Sperimentale, Universitá di Bologna, Via S. Giacomo, 12, E-40126 Bologna, Italy.
}

Supplementary Material (two figures) for this paper is available at: http://dx.doi.org/10.1387/ijdb.113432mi

Final, author-corrected PDF published online: 16 March 2012 
the control of folding and quality of cellular proteins. Failure in the HSP-mediated protection mechanisms results in the accumulation of misfolded proteins, which is a common element for many protein conformation disorders. HSP nomenclature, typically based on their molecular weight, discriminates five major families: HSP100s, HSP90s, HSP70s, HSP60s, and small heat shock proteins (sHSPs). Although most of HSPs are constitutively expressed and required for normal cell development and functioning, several inducible members can be transcriptionally upregulated by stress events. Basically, HSPs function ensures fidelity and proper regulation of eukaryotic protein expression, and allows cells to adapt to gradual changes in their environment and to survive in otherwise lethal conditions. It is worthwhile also to recall that HSPs have been found to be involved in stem cell proliferation, inhibition of apoptosis and cancer (Lemieux et al., 1997; Garrido et al., 1998; Helmbrecht et al., 2000; Joly et al., 2010). Some HSPs are overexpressed in several malignant tumours, and their inhibition has recently been regarded as a promising therapeutic tool against various cancers (Didelot et al., 2007).

While the function of HSPs as molecular chaperones has been extensively characterized in differentiated cells, their role in stem cells remains unclear. It has been found that high levels of $h s p$ expression and elevated stress tolerance characterize mammalian embryonic stem (ES) cells. These transcripts are downregulated upon differentiation, suggesting that stress defence, including HSPs function, is crucial for stem cells (Saretzki et al., 2004; Hernebring et al., 2006; Baharvand et al., 2008; Saretzki et al., 2008). A role for HSPs in proliferation and self-renewal of stem cells has been suggested: HSPs might directly trigger or protect signaling intermediates in essential proliferative/differentiation cascades (Prinsloo et al., 2009). HSPs have also been related to differentiation events of hematopoietic stem cells through a mechanism crucial in protecting transcription factors which drive proliferation and differentiation towards a specific lineage (D'Alessandro et al., 2010). Due to the presence of neoblasts, planarians may significantly contribute to the understanding of the role of HSPs in stem cells. While some studies have mainly focused on the role of HSPs as biomarkers of genotoxic stress in planarians (Guecheva et al., 2003; Sánchez Navarro et al., 2009), only recently hsp gene expression and function has been characterized in these organisms with the aim
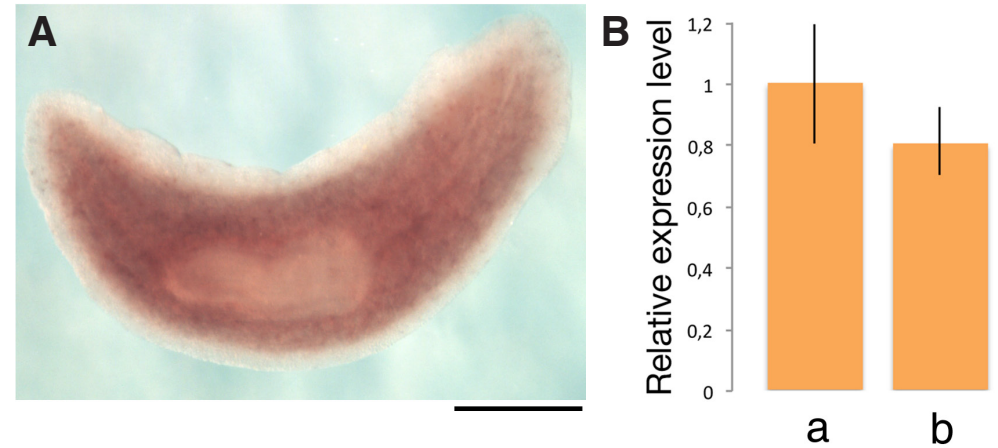

Fig. 1. Characterization of a small hsp gene in D. japonica. (A) Whole mount in situ hybridization of Djshsp in an intact D. japonica (ventral view). Scale bar: $1 \mathrm{~mm}$. (B) Expression level of Djshsp in cell fractions obtained by filtration through nylon meshes, visualized by real time RT-PCR. Expression level is indicated in relative units, assuming the value of 50 $\mu \mathrm{m}$ nylon meshes as unitary. The expression values of $8 \mu \mathrm{m}$ (c) and $20 \mu \mathrm{m}$ (b) nylon mesh samples were compared with those of $50 \mu \mathrm{m}$ (a) nylon mesh samples using an analysis of variance (ANOVA). ${ }^{*} P<0.05$.

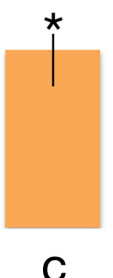

to assess how these proteins contribute to the mechanisms that regulate stem cell activity (Conte et al., 2009, 2010; FernándezTaboada et al., 2011). Table I summarizes the current information on $h s p$ genes recently characterized in planarians.

\section{Heat shock protein (hsp) genes in planarians}

\section{Small hsp genes}

The small HSP (sHSP) family consists of highly heterogeneous members, associated with nuclei, cytoskeleton and membranes, that have been implicated in maintaining protein homeostasis, but also in protein folding diseases and cancer (Kriehuber et al., 2010). In addition, some shsps genes have been found highly expressed in mammalian ES cells, and downregulated upon differentiation (Saretzki etal., 2004; Saretzki et al., 2008). The typical trait of sHSPs is a conserved $\alpha$-crystallin core domain, which refers to the most famous family member, the eye-lens protein $\alpha$-crystallin (Horwitz, 2003). We recently identified a shsp-related gene in $D$. japonica (unpublished data). Comparison of the deduced amino acids with protein data bank showed that this gene ( $D j s h s p$ ) encodes a putative polypeptide belonging to the $\alpha$-crystallin small heat shock proteins superfamily. An almost identical gene was identified by in silico analysis of the genome of Schmidtea mediterranea(Supplementary Fig. 1). Although some members of the group of sHSPs seem to play a neuroprotective role in the brain (Kirbach and Golenhofen, 2011), our preliminary results do not provide any clear evidence of preferential distribution of Djshsp transcripts in the planarian CNS. Djshsp transcripts are in fact ubiquitously distributed in the planarian body, and no preferential accumulation in the CNS has been detected (Fig. 1A). Real time RT-PCR using RNA obtained from dissociated cell fractions, enriched in neoblasts by progressive filtering through nylon meshes of different pore size (Salvetti et al., 2005; Rossi et al., 2007), provided further information on the cell type(s) expressing Djshsp. We found that Djshsp was preferentially concentrated in the fraction that included cells of large/ medium size (Fig. 1B). Moreover, since Djshspexpression was not affected by X-ray treatment (not shown), this indicates that Djshsp is not expressed in neoblasts. In addition the genomic survey of $S$. mediterranea also identified three different regions with significant similarity to the $\alpha$-crystallin core domain (v31.015603; v31.007045; v31.000527) suggesting that other shsp genes are present in planarians. Further studies are required to investigate the possibility that the genes encoding these putative SHSPs are involved in cytoprotection mechanisms of planarian stem cells.

\section{hsp40/DnaJ genes}

A proteomics approach to decipher the molecular nature of planarian stem cells recently identified a member of the $h s p 40 / D n a J$ gene family as a stem cell-specific hsp gene (Fernández-Taboada et al., 2011). The complete $h s p 40$ planarian gene, identified in silico in $S$. mediterranea (genomic region v31.000.171), encodes a protein of 345 aminoacids, typified by the conserved J domain at the $\mathrm{N}$ terminus followed by a Gly/Phe-rich region (Supplementary Fig. 2). The presence of HSP70 binding motifs in the $\mathrm{J}$ domain suggests functional interaction with HSP70s. HSP40 members are in fact important 
TABLE 1

\section{PLANARIAN HSP GENES}

\begin{tabular}{|c|c|c|c|c|c|}
\hline Planarian gene & Expression/localization & $\begin{array}{l}\text { Irradiation } \\
\text { sensitivity }\end{array}$ & RNAi phenotype & Proposed function & References \\
\hline Djshsp & Ubiquitously distributed & $U$ & N.D. & Unknown & Work in progress \\
\hline Smed hsp 40 & Neoblasts & S & Tissue regression, lysis in several weeks & Stem cell self-renewal/proliferation & Fernández-Taboada et al. (2011) \\
\hline$D j / S m e d ~ h s p 60$ & Neoblasts & S & Tissue regression & Cytoprotection/immunoregulatory effects & $\begin{array}{l}\text { Conte et al. (2010) } \\
\text { Fernández-Taboada et al. (2011) }\end{array}$ \\
\hline$D j / S m e d ~ h s p 70$ & Ubiquitously distributed & U & N.D. & Unknown & $\begin{array}{l}\text { Conte et al. (2009) } \\
\text { Ma et al. (2009) }\end{array}$ \\
\hline Dj/Smed mot & $\begin{array}{l}\text { Neoblasts and committed } \\
\text { progeny }\end{array}$ & S & $\begin{array}{l}\text { Tissue regression, Curling around the ventral } \\
\text { surface, death in several weeks }\end{array}$ & Stem cell viability/ sequestration of p53 & $\begin{array}{l}\text { Conte et al. (2009) } \\
\text { Fernández-Taboada et al. (2011) }\end{array}$ \\
\hline$D j / S m e d ~ h s p 90$ & Gastrodermis and neoblasts & S & $\begin{array}{l}\text { Reduction of animal size, inability to eat, death } \\
\text { in several weeks }\end{array}$ & Cytoprotection & Conte et al. (2011) \\
\hline
\end{tabular}

N.D.: not determined; U: unsensitive; S: sensitive

for the function of HSP70s chaperones, primarily by stimulating their ATPase activity (Qiu et al., 2006). Based on the presence/ absence of the Gly/Phe-rich region and/or cysteine repeats, the HSP40 proteins have been categorized into three groups, which may show functional diversity (Qiu et al., 2006). The Gly/Phe-rich region classifies the planarian HSP40 as a type II HSP40 protein. Interestingly, the co-chaperone Mrj, a mammalian member of the type II group of HSP40 (also known as DnaJB6), has been found to be necessary for self-renewal of neural stem cells (Watson et al., 2009). It is intriguing to speculate that a conserved type II HSP40 co-chaperone-mediated activity may exist for the control of self-renewal and proliferation of stem cells in diverse organisms. Further analysis of the planarian Hsp40/DnaJ homolog will be useful to unravel the function of this molecular co-chaperone in planarian stem cells.

\section{hsp60 genes}

HSP60s are well characterized members of the 'chaperonin' class of proteins, mainly localized in mitochondria, but also detected in the cytosol of eucaryotic cells. These proteins act as oligomers and play an essential role in the folding of many proteins, avoiding possible misfoldings. Recent work also demonstrates that HSP60 can be detected extracellularly, as well as in the cell membrane, and the extracellular location is not only the consequence of cell destruction, but the result of an active secretion mechanism (Cappello et al., 2008; Ohashi et al., 2009). Extracellular complexes of HSPs and peptides appear to act as 'danger signals' to the immune system to trigger an innate immune response. For example they can have effect as ligands of the receptors of the Toll-like (TLR) signal-transduction pathway causing apoptosis or cell survival, depending on the status of the stressed cell (Ohashi et al., 2000; Asea, 2008). Interestingly, hsp60 transcripts have been found up-regulated in stem and cancer cells (Baharvand et al., 2008;

Fig. 2. Expression of Djhsp60 and phenotypic effects of its RNAimediated knockdown in D. japonica. (A-C) Whole mount in situ hybridization in 30 Gy-irradiated planarians. (A) An unirradiated planarian. (B) 3 days after irradiation. (C) 7 days after irradiation. (D-G) Bright-field images of Djhsp60 (RNAi) phenotypes: the planarian fragments were analyzed 5 days after amputation. (D,E) head fragments. (D) A waterinjected control. (E) Djhsp60 (RNAi). (F,G) tail fragments. (F) A water-injected control. (G) Djhsp60 (RNAi). (H-K) Djhsp60 whole mount in situ hybridization in regenerating fragments. (H) $A$ head fragment, 2 days after amputation. (I) A head fragment, 4 days after amputation. (J) A tail fragment, 2 days after amputation. (K) A tail fragment, 4 days after amputation. Dorsal view, anterior is up. Scale bars: $1 \mathrm{~mm}$.
Cappello et al., 2008). A gene encoding a potential HSP60 protein has been identified in the planarian $D$. japonica ( $D j h s p 60)$ (Rossi et al., 2007; Conte et al., 2010) and a very similar gene is present in the related species $S$. mediterranea $(\mathrm{H} .21 .6 \mathrm{~h}$; Eisenhoffer et al., 2008). Whole-mount in situhybridization of intact animals provided evidence that the expression pattern of Djhsp60 is reminiscent of the parenchymal distribution of neoblasts, accordingly with the transcriptional profile detected by microarray analysis (Rossi et al., 2007). However, after a lethal dose of X-ray irradiation (30Gy), we observed transient upregulation of $h s p 60$ transcripts in postmitotic tissues, such as intestine and nerve cells, while the parenchymal expression declined at undetectable level (Fig. 2A-C). The intestinal Djhsp60hybridization signal may be already present in unirradiated
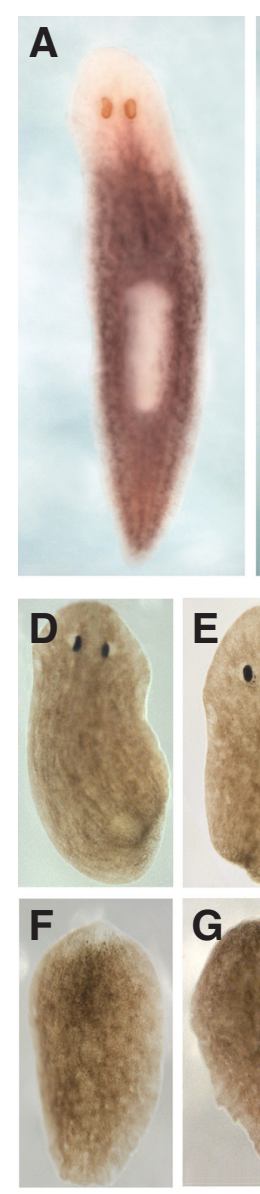

B
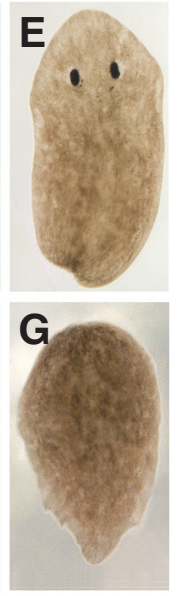

C

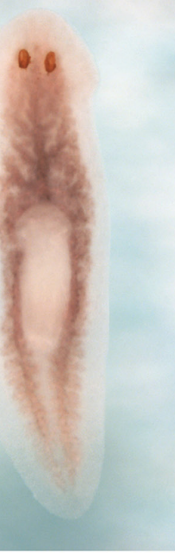

H
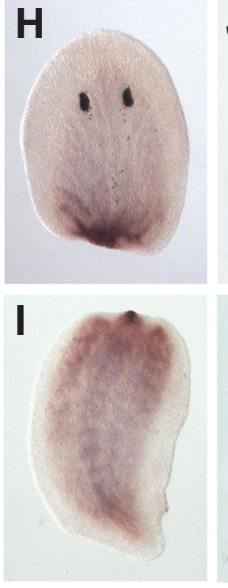

J

$\mathbf{J}$

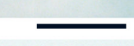

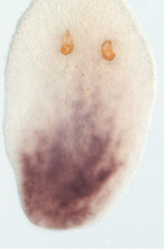

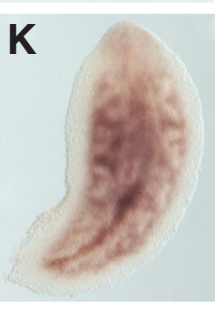


animals, masked by the high signal in the parenchyma. However it is interesting to note that a similar behavior after irradiation has already been described for another $h s p$-related gene in planarians (Djmot: Conte et al., 2009). The X-ray-induced transient activation of transcriptional response of $h s p 60$ and Djmot suggests that both genes, although constitutively expressed in neoblasts, also represent a 'first line of defence' for particularly susceptible postmitotic cells, playing relevant 'chaperone'functions in damage-associated responses. RNAinterference (RNAi) demonstrates that the function of $D j h s p 60$ is required for neoblast viability and regeneration. In fact, Djhsp60RNAi caused some tissue regression in intact animals (data not shown). When amputated, the injected fragments appeared unable to regenerate (Fig. 2D-G). However only a limited number of Djhsp60(RNAi) planarians (23/150) did not regenerate. The majority of the injected specimens regenerated, but some of them exhibited a smaller blastema. The phenotypes appeared due to a decreased number of neoblasts, as deduced by the reduced expression of the neoblast-specific marker Djmcm2 (data not shown). Although we cannot exclude that DjHSP60 plays only an auxiliary role in the mechanisms involved in survival/maintenance of planarian stem cells, we think that these results may be due to the effect of other genes that could compensate for the loss of $h s p 60$ function. To support this hypothesis we observed that Djhsp60 (RNAi planarians) were able to completely recover their regenerative abilities after the treatment.

Although constitutively expressed in neoblasts, Djhsp60 is transiently upregulated in the regeneration blastema, a region devoid of neoblasts (Fig. $2 \mathrm{H}-\mathrm{K}$ ). It is interesting to note that transient activation of Djhsp60 homologs has been detected in the early blastema of other regenerating systems, for example, during fin

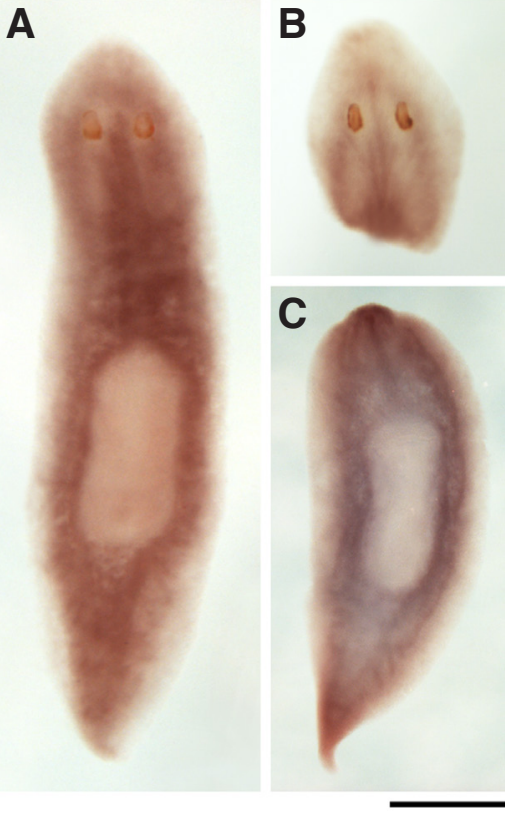

Fig. 3. Expression pattern of Djhsp70, as visualized by whole mount in situ hybridization. (A) An intact planarian. (B) A head fragment regenerating a tail, 3 days after amputation. (C) A tail fragment regenerating a head, 3 days after amputation. Dorsal view. Scale bar: $1 \mathrm{~mm}$. regeneration in fish or limb regeneration in amphibia (Makino et al., 2005; Pearl et al., 2008). Transient overexpression of some HSPs, including HSP60, has also been observed during the early phase of liver regeneration in mouse, and inhibition of these proteins delayed the progress of the process (Shi et al., 2007). Although the function of HSP60 in blastemal cells is still unknown, these findings underline the central role of HSP60 in regeneration. To what extent regeneration may trigger a stress response? It has been suggested that, as a chaperonin, HSP60 plays a protective role for the correct folding of newly formed proteins. Several reports also indicate that HSP60 plays immunoregulatory functions, moving abnormal peptides from inside to the cell surface and warning the immune system that the cell has become stressed (Habich et al., 2007; Trivedi et al., 2010). Amputation trauma could generate a stressful environment that activates an inflammatory status, physiologically regulated by the immune system. Both HSP60-mediated cytoprotective and immunoregulatory effects might be fundamental to accomplish and maintain the appropriate levels of thousands of proteins, necessary to ensure the complex and dynamic succession of events that determine the regenerative success.

\section{hsp70 genes}

The 70-kDa heat shock proteins (HSP70s) represent the largest and well-studied stress-related protein family, including members related to the prokaryotic chaperone, referred to as DnaK (Genevaux et al., 2007). Many proteins belonging to this family have been identified from yeasts to humans. Some of these appear strictly inducible, i.e. expressed only under stress conditions, while the constitutive (or cognate) counterparts are expressed in unstressed cells. The various HSP70s are found in the cytosol and in organelles, such as the ER, mitochondria, and chloroplasts, where assist a large variety of protein folding processes, preventing aggregation and promoting the native state. Under stress, HSP70s appear to play an essential role in refolding of misfolded and aggregated proteins (Mayer and Bukau, 2005). The various members of this family share structural and biochemical properties. All of them in fact bind and hydrolize ATP by an ATPase domain and interact with other proteins by a protein binding domain.

Although our in silico search revealed that several $h s p 70$-related genes are present in the planarian genome (not shown), only two different members of this family have been characterized so far: Djhsp70 and Djmot (Conte et al., 2009; Ma et al., 2009). Djhsp70 is an inducible gene, significantly up-regulated in response to temperature changes, amputation and starvation (Ma et al., 2009). Our whole mount in situ hybridizations demonstrated that Djhsp70 transcripts are widely distributed along the planarian body and up-regulated in the regenerative blastema (Fig. $3 A-C$ ).

Djmot encodes a peculiar heat-uninducible HSP70 member, showing high similarity with mammalian Mortalin. Djmottranscripts have been detected in neoblasts and early progenitors of intact and regenerating planarians (Conte et al., 2009, 2010). These results implicate that planarian stem cells, similarly to mammalian ES cells (Saretzki et al., 2004), constitutively express high levels of a Mortalin-like protein that are progressively eliminated when these cells undergo differentiation. Although Mortalin is a pleiotropic chaperone, a major function of this protein has been related to the control of cellular immortality (Wadhwa et al., 2002). After Djmot RNAi, planarians showed ventral curling and lysis and failed to regenerate (Conte et al., 2009). This phenotype, typically observed when stem cells are eliminated from planarians (Pearson and Sánchez Alvarado, 2010), indicates that this protein plays a major role in the self-preservation program of planarian stem cells. Does this ability implement the basic functionalities that allow these cells to survive to stochastic processes that damage cells in the environment? Although the mechanism(s) by which DjMot acts in vivo remain to be determined, detection of a variable number of cells with a senescent morphology in Djmot(RNAi) planarians (never observed in control animals) strongly supports this possibility. As senescence-associated biomarkers are not available in planarians, we can only hypothesize that a reduced amount of 

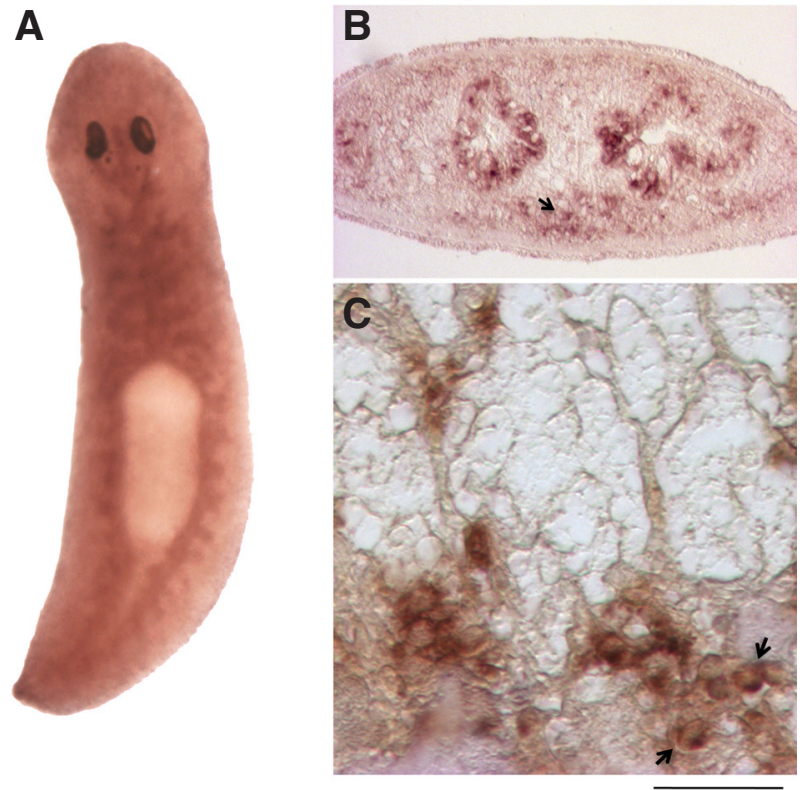

Fig. 4. Expression of Djhsp90 in D. japonica. (A) Whole mount in situ hybridization in an intact planarian. $(\mathbf{B}, \mathbf{C})$ In situ hybridization on transverse wax sections, dorsal is up. (B) A transverse section showing hybridization signal in the gut branches. Some Djhsp90-expressing cells can be also detected in the parenchyma (arrow). (C) Enlarged view of the basal region of a gut branch showing some labelled neoblast-like cells (arrows). Scale bar: $1 \mathrm{~mm}$ in (A); $200 \mu \mathrm{m}$ in (B) and $50 \mu \mathrm{m}$ in (C).

this protein triggers a senescent status in neoblasts. Vertebrate and invertebrate mortalins have the ability to prevent senescence and apoptosis and promote cell immortalization by sequestering p53 protein in the cytoplasm (Wadhwa et al., 2002; Walker et al., 2006; Sherman et al., 2007). Cross-reaction with a heterologous antibody, designed against the mortalin p53-binding region also suggests that Djmot possesses an active p53-binding domain. In this context we speculate that the specific expression of Djmot in neoblasts could be linked to the need to ensure constitutive activation of an efficient cell immortalization mechanism, crucial to guarantee the proliferative efficiency of the whole planarian stem cell system.

\section{hsp90 genes}

Heat shock protein 90 (HSP90) is one of the most abundant chaperones orchestrating folding, maintenance of structural and conformational integrity of a large number of target substrates, including transcription factors and kinases. Consistent with its role in maintaining the structure and function of key regulatory elements, it has been found that inactivation of HSP90 machinery may reveal cryptic genetic variations, influencing signal transduction, chromatin remodelling, epigenetic regulation or apoptosis (Sato and Siomi, 2010). Furthermore, a fraction of HSP90 has recently been identified at the cell surface and has been correlated with cell motility and invasion capability of cancer cells. HSP90 proteins consist of three domains, an N-terminal, ATP-binding domain, a middle (M), ATP-hydrolysis regulating domain and a C-terminal domain. The chaperoning activity of HSP90 depends on its ability to hydrolyze ATP, as well as on its potential to recruit and form stable complexes with Hsp70/Hsp90/Organizing Protein (Hop) co-chaperones, through the conserved EEVD C-terminus motif.

We recently reported the first characterization of an $h s p 90$-related gene (Djhsp90) in the planarian D. japonica (Conte et al., 2011). The dynamics of changes in the expression profile in response to various stress conditions clearly demonstrates that Djhsp90 encodes a stress-induced protein. We also observed that the Djhsp90 functional inactivation by RNAi induced lethal phenotypic consequences in planarians. Most of the hsp90(RNAi) animals became in fact very small in size, were unable to eat and died in a few weeks. Our data support the rationale that the activity of hsp90 achieves in vivo critical cytoprotective effects in the gastrodermis of planarians. The presence of Djhsp90 transcripts in the intestine appears to sustain this role (Fig. 4A,B; Conte et al., 2011). However, expression of Djhsp90 was also detected in the parenchyma of unstressed animals, localized in small neoblastlike cells (Fig. 4C). Although Djhsp90 expression may be limited only to neoblasts committed towards the gastrodermal fate (Conte et al., 2011), the multiplicity of roles assigned to HSP90 proteins supports the possibility that DjHSP90 plays different function(s) in planarian stem cells, possibly influencing signal transduction and/or chromatin remodelling mechanisms. Further studies are necessary to identify the relationships between DJHSP90 and planarian stem cells.

\section{Concluding remarks}

It is becoming increasingly apparent that the activity of HSPs plays a key role in the protein homeostasis of stem cells, controlling the proper protein-folding, binding interactions and subcellular or extracellular position of individual proteins. Embryonic stem cells express high levels of HSPs to ensure protective functions that are essential for maintaining their unlimited potential for growth and differentiation. Somatic stem cells, generally recruited to areas of tissue damage and regeneration in adult organisms, also constitutively activate HSPs to overcome various stress situations. In the present review we summarized recent work describing the expression and function of a number of $h s p s$ genes in planarians, in an attempt to better understand the role of the stress response in the control of the exceptional stem cell system of these organisms. It has been reported that, while activation of hsps genes in specialized cells generally occurred in response to stress, most of these genes were constitutively expressed in planarian stem cells. RNAi-mediated knockdown of specific hsp members negatively affected stem cell growth and regeneration potential. These results demonstrate that, similarly to that found in $\mathrm{mES}$, specific HSPs play essential roles on planarian stem cell growth and viability. Elucidation of the interactions among different HSPs, as well as their relationships with other molecules (such as those of apoptotic pathways), represents a future goal of this research. In addition, characterization of $h s p$ genes in organisms with exceptional regenerative abilities, such as planarians, has the potential to enhance our knowledge on the molecular mechanisms that cause their up or downregulation during stem cell differentiation. Studies on other animal models of regeneration demonstrate that, similarly to that observed in planarians, enhanced expression of hsps occurs in response to the initial trauma of wounding. Upregulation of $h s p$ genes certainly plays a role in maintaining protein homeostasis necessary to initiate the regeneration process, however other functions related for example to the activation of mechanisms of inflammatory response cannot 
be ruled out. Ultimately, understanding the molecular aspects that control the local microenvironment after wounding could be of importance for regenerative medicine applications in humans.

\section{References}

ASEA, A. (2008). Heat shock proteins and toll-like receptors. Handb Exp Pharmacol 183: $111-127$.

BAHARVAND, H., FATHI, A., GOURABI, H., MOLLAMOHAMMADI, S. and SALEKDEH, G.H. (2008). Identification of mouse embryonic stem cell-associated proteins. J Proteome Res 7: 412-423.

CAPPELLO, F., CONWAY DE MACARIO, E., MARASÀ, L., ZUMMO, G. and MACARIO, A.J. (2008). Hsp60 expression, new locations, functions and perspectives for cancer diagnosis and therapy. Cancer Biol Ther 7: 801-809.

CONTE, M., DERI, P., ISOLANI, M.E., MANNINI, L. and BATISTONI, R. (2009). A mortalin-like gene is crucial for planarian stem cell viability. Dev Bio/334: 109-118.

CONTE, M., ISOLANI, M.E., DERI, P., MANNINI, L. and BATISTONI, R. (2010). Characterization of $h s p$ genes in planarian stem cells. Belg J Zool 140: 137-143.

CONTE, M., ISOLANI, M.E., DERI, P., MANNINI, L. and BATISTONI, R. (2011). Expression of $h s p 90$ mediates cytoprotective effects in the gastrodermis of planarians. Cell Stress Chaperones 16: 33-39.

D'ALESSANDRO, A., GRAZZINI, G., GIARDINA, B. and ZOLLA, L. (2010). In silico analyses of proteomic data suggest a role for heat shock proteins in umbilical cord blood hematopoietic stem cells. Stem Cell Rev 6: 532-547.

DIDELOT, C., LANNEAU, D., BRUNET, M., JOLY, A.L., DE THONEL, A., CHIOSIS, G. and GARRIDO, C. (2007). Anti-cancer therapeutic approaches based on intracellular and extracellular heat shock proteins. Curr Med Chem 14: 2839-2847.

EISENHOFFER, G.T., KANG,H. and SÁNCHEZ ALVARADO, A. (2008). Molecular analysis of stem cells and their descendants during cell turnover and regeneration in the planarian Schmidtea mediterranea. Cell Stem Cell 3: 327-339.

FERNÁNDEZ-TABOADA, E., RODRÍGUEZ-ESTEBAN, G., SALÓ, E. and ABRIL, J.F. (2011). A proteomics approach to decipher the molecular nature of planarian stem cells. BMC Genomics 12:133.

GARRIDO, C., FROMENTIN, A., BONNOTTE, B., FAVRE, N., MOUTET, M., ARRIGO, A.P., MEHLEN, P. and SOLARY, E. (1998). Heat shock protein 27 enhances the tumorigenicity of immunogenic rat colon carcinoma cell clones. Cancer Res 58 : 5495-5499.

GENEVAUX, P., GEORGOPOULOS, C. and KELLEY, W.L. (2007). The Hsp70 chaperone machines of Escherichia coli: a paradigm for the repartition of chaperone functions. Mol Microbiol 66: 840-857.

GENTILE, L., CEBRIÀ, F. and BARTSCHERER, K. (2011). The planarian flatworm: an in vivo model for stem cell biology and nervous system regeneration. Dis Model Mech 4: 12-19.

GUECHEVA, T.N., ERDTMANN, B., BENFATO, M.S. and HENRIQUES, J.A. (2003). Stress protein response and catalase activity in freshwater planarian Dugesia (Girardia) schubarti exposed to copper. Ecotoxicol Environ Saf 56: 351-357.

$\mathrm{HABICH}$, C. and BURKART, V. (2007). Heat shock protein 60: regulatory role on innate immune cells. Cell Mol Life Sci 64: 742-751.

HANDBERG-THORSAGER, M., FERNANDEZ, E. and SALÓ, E. (2008). Stem cells and regeneration in planarians. Front Biosci 13: 6374-6394.

HELMBRECHT, K., ZEISE, E. and RENSING, L. (2000). Chaperones in cell cycle regulation and mitogenic signal transduction: a review. Cell Prolif 33: 341-365.

HERNEBRING, M., BROLÉN, G., AGUILANIU, H., SEMB, H. and NYSTRÖM, T. (2006). Elimination of damaged proteins during differentiation of embryonic stem cells. Proc Natl Acad Sci USA 103: 7700-7705.

HORWITZ, E.M. (2003). Stem cell plasticity: the growing potential of cellular therapy. Arch Med Res 34: 600-606.

JOLY, A.L., WETTSTEIN, G., MIGNOT, G., GHIRINGHELLI, F. and GARRIDO, C. (2010). Dual role of heat shock proteins as regulators of apoptosis and innate immunity. J Innate Immun 2: 238-247.

KIRBACH, B.B. and GOLENHOFEN, N. (2011). Differential expression and induction of small heat shock proteins in rat brain and cultured hippocampal neurons. $J$ Neurosci Res 89: 162-175.

KRIEHUBER, T., RATTEI, T., WEINMAIER, T., BEPPERLING, A., HASLBECK, M. and
BUCHNER, J. (2010). Independent evolution of the core domain and its flanking sequences in small heat shock proteins. FASEB J 24: 3633-3642.

LEMIEUX, P., OESTERREICH, S., LAWRENCE, J.A., STEEG, P.S., HILSENBECK, S.G., HARVEY, J.M. and FUQUA, S.A. (1997). The small heat shock protein hsp27 increases invasiveness but decreases motility of breast cancer cells. Invasion Metastasis 17: 113-123.

LINDQUIST, S. and CRAIG, E.A. (1988). The heat-shock proteins. Annu Rev Genet 22: $631-77$.

MA, K.X., CHEN, G.W., LOU, H. and FEI, L.N. (2009). Cloning and expression analysis of $h s p 70$ gene from freshwater planarian Dugesia japonica. Biologia64: 1018-1024.

MAKINO, S., WHITEHEAD, G.G., LIEN, C.L., KIM, S., JHAWAR, P., KONO, A KAWATA, Y. and KEATING, M.T. (2005). Heat-shock protein 60 is required for blastema formation and maintenance during regeneration. Proc Natl Acad Sci USA 102: 14599-14604.

MAYER, M.P. and BUKAU, B. (2005). Hsp70 chaperones: cellular functions and molecular mechanism. Cell Mol Life Sci 62: 670-684.

OHASHI, K., BURKART, V., FLOHÉ, S. and KOLB, H. (2000). Cutting edge: heat shock protein 60 is a putative endogenous ligand of the toll-like receptor- $4 \mathrm{com}$ plex. J Immunol 164: 558-561.

OHASHI, S., ATSUMI, M. and KOBAYASHI, S. (2009). HSP60 interacts with YB-1 and affects its polysome association and subcellular localization. Biochem Biophys Res Commun 385: 545-550.

PEARL, E.J., BARKER, D., DAY, R.C. and BECK, C.W. (2008). Identification of genes associated with regenerative success of Xenopus laevis hindlimbs. BMC Dev Biol 8: 66.

PEARSON, B.J. and SÁNCHEZ ALVARADO, A. (2010). A planarian p53 homolog regulates proliferation and self-renewal in adult stem cell lineages. Development 137: 213-221.

PRINSLOO, E., SETATI, M.M., LONGSHAW, V.M. and BLATCH, G.L. (2009). Chaperoning stem cells: a role for heat shock proteins in the modulation of stem cell self-renewal and differentiation? Bioessays 31: 370-377

QIU, X.B., SHAO, Y.M., MIAO, S. and WANG, L. (2006). The diversity of the DnaJ/ Hsp40 family, the crucial partners for Hsp70 chaperones. Cell Mol Life Sci 63 : 2560-2570.

RANDO, T.A. (2006). Stem cells, ageing and the quest for immortality. Nature 441 1080-1086.

ROSSI, L., SALVETTI, A., MARINCOLA, F.M., LENA, A., DERI, P., MANNINI, L., BATISTONI, R., WANG, E. and GREMIGNI, V. (2007). Deciphering the molecular machinery of stem cells: a look at the neoblast gene expression profile. Genome Biol 8: R62.

SAHIN, E. and DEPINHO, R.A. (2010). Linking functional decline of telomeres, mitochondria and stem cells during ageing. Nature 464: 520-528.

SALVETTI, A., ROSSI, L., LENA, A., BATISTONI, R., DERI, P., RAINALDI, G., LOCCI, M.T., EVANGELISTA, M. and GREMIGNI, V. (2005). DjPum, a homologue of Drosophila Pumilio, is essential to planarian stem cell maintenance. Development 132: 1863-1874

SÁNCHEZ NAVARRO, B., MICHIELS, N.K., KÖHLER, H.R. and D'SOUZA, T.G (2009). Differential expression of heat shock protein 70 in relation to stress type in the flatworm Schmidtea polychroa. Hydrobiol 636: 393-400.

SARETZKI, G., ARMSTRONG, L., LEAKE, A., LAKO, M. and VON ZGLINICKI, T. (2004). Stress defense in murine embryonic stem cells is superior to that of various differentiated murine cells. Stem Cells 22: 962-971.

SARETZKI, G., WALTER, T., ATKINSON, S., PASSOS, J.F., BARETH, B., KEITH, W.N., STEWART, R., HOARE, S., STOJKOVIC, M, . ARMSTRONG, L., VONZGLINICKI, T. and LAKO. M. (2008). Downregulation of multiple stress defense mechanisms during differentiation of human embryonic stem cells. Stem Cells 26: 455-464.

SATO, K. and SIOMI, H. (2010). Is canalization more than just a beautiful idea? Genome Biol 11: 109.

SHERMAN, M.Y., GABAI, V., O'CALLAGHAN, C. and YAGLOM, J. (2007). Molecular chaperones regulate p53 and suppress senescence programs. FEBS Lett 581: 3711-3715.

SHI, Q., DONG, Z. and WEI, H. (2007). The involvement of heat shock proteins in murine liver regeneration. Cell $\mathrm{Mol}$ Immunol 4: 53-57.

TRIVEDI, V., GADHVI, P., CHORAWALA, M. and SHAH, G. (2010). Role of heat shock proteins in immune response and immunotherapy for human cancer. Int $J$ 
Pharm Sci Rev and Res 2: 57-62.

WADHWA, R., TAIRA, K. and KAUL, S.C. (2002). An Hsp70 family chaperone, mortalin/mthsp70/PBP74/Grp75: what, when, and where? Cell Stress Chaperones 7: 309-316.
WALKER, C., BÖTTGER, S. and LOW, B. (2006). Mortalin-based cytoplasmic sequestration of p53 in a nonmammalian cancer model. Am J Pathol 168: 1526-1530.

WATSON, E.D., MATTAR, P., SCHUURMANS, C. and CROSS, J.C. (2009). Neural stem cell self-renewal requires the Mrj co-chaperone. Dev Dyn 238: 2564-2574.

\section{Further Related Reading, published previously in the Int. J. Dev. Biol.}

\section{Planarian regeneration: achievements and future directions after 20 years of research}

Emili Saló, Josep F. Abril, Teresa Adell, Francesc Cebriá, Kay Eckelt, Enrique Fernández-Taboada, Mette Handberg-Thorsager, Marta Iglesias, M Dolores Molina and Gustavo Rodríguez-Esteban

Int. J. Dev. Biol. (2009) 53: 1317-1327

\section{Diverse miRNA spatial expression patterns suggest important roles in homeostasis and} regeneration in planarians

Cristina González-Estévez, Varvara Arseni, Roshana S. Thambyrajah, Daniel A. Felix and A. Aziz Aboobaker

Int. J. Dev. Biol. (2009) 53: 493-505

Two $\mathrm{msh} / \mathrm{msx}$-related genes, Djmsh1 and Djmsh2, contribute to the early blastema growth during planarian head regeneration

Linda Mannini, Paolo Deri, Vittorio Gremigni, Leonardo Rossi, Alessandra Salvetti and Renata Batistoni

Int. J. Dev. Biol. (2008) 52: 943-952

From Planarians to Mammals - the many faces of regeneration

Jerzy Moraczewski, Karolina Archacka, Edyta Brzoska, Maria-Anna Ciemerych, Iwona Grabowska, Katarzyna Janczyk-Ilach, Wladyslawa Streminska and Malgorzata Zimowska Int. J. Dev. Biol. (2008) 52: 219-227

Expression of DjXnp, a novel member of the SNF2-like ATP-dependent chromatin remodelling genes, in intact and regenerating planarians

Leonardo Rossi, Paolo Deri, Ilaria Andreoli, Vittorio Gremigni, Alessandra Salvetti and Renata Batistoni

Int. J. Dev. Biol. (2003) 47: 293-298

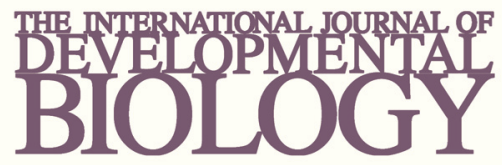

Volume 54 Nos. $6 / 7$
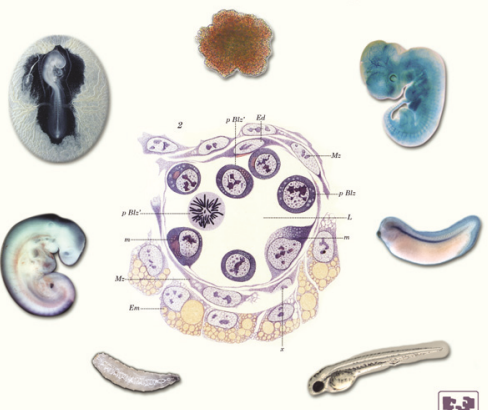

Developmental Hematopoiesis
5 yr ISI Impact Factor $(2010)=2.961$

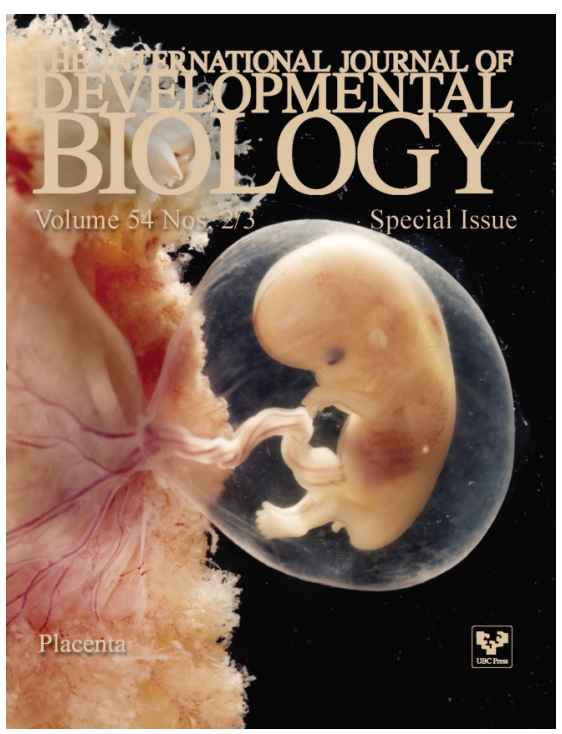

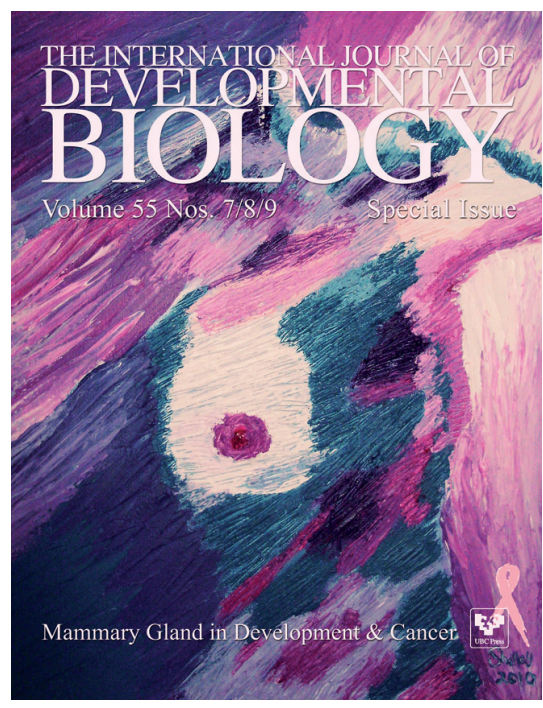

THE INTERNATIONAL JOURNAL OF

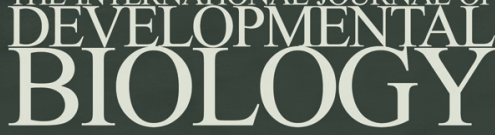

Volume 55 Nos. $4 / 5$

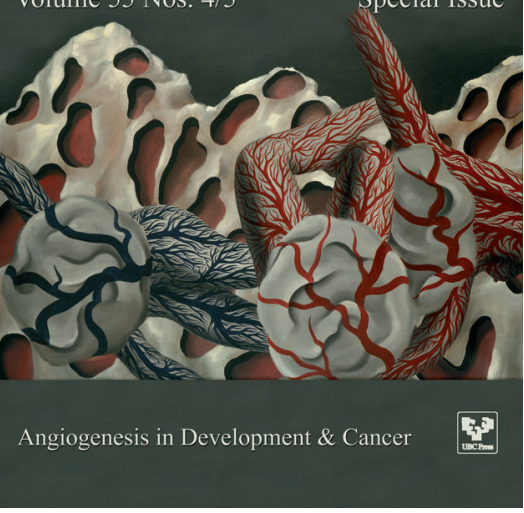

